\title{
The relative importance and interactions of CMR-derived parameters of ventricular mechanics in the prediction of death and transplant late after the Fontan operation
}

\author{
Rahul H Rathod ${ }^{1,2^{*}}$, Lynn A Sleeper ${ }^{1,2}$, Sunil J Ghelani ${ }^{1,2}$, Ellen M Keenan ${ }^{1}$, David M Harrild ${ }^{1,2}$, Andrew J Powell ${ }^{1,2}$, \\ Tal Geva ${ }^{1,2}$
}

From 19th Annual SCMR Scientific Sessions

Los Angeles, CA, USA. 27-30 January 2016

\section{Background}

We have previously shown that a larger indexed enddiastolic volume $\left(E D V_{i}\right)$ of a functional single ventricle as determined by cardiac magnetic resonance (CMR) is an independent predictor of death and heart transplant late after the Fontan operation. Other reports have suggested that decreased ventricular strain and ejection fraction (EF) are associated with poor outcomes. The objective of this study was to identify the relative importance and interactions of CMR-based parameters for risk of death and transplant after the Fontan operation.

\section{Methods}

Clinical CMR studies from $1 / 2002$ to $1 / 2015$ were retrospectively reviewed. Ventricular size and function measurements were calculated using commercially available software (Medis Medical Imaging Systems, Leiden the Netherlands). Global circumferential strain (GCS) and longitudinal strain (GLS) were measured for the single or dominant ventricle at the mid-ventricular level using commercial software (TomTec Imaging Systems, Unterschleissheim, Germany). The primary endpoint was defined as time to death or listing for heart transplantation. Classification and regression tree (CART) survival analysis was performed to identify the subgroups at highest risk for the endpoint without pre-specification of possible interactions. Candidate predictors were indexed EDV, indexed end-systolic volume, EF,

${ }^{1}$ Cardiology, Boston Children's Hospital, Boston, MA, USA

Full list of author information is available at the end of the article indexed ventricular mass, GCS, and GLS. Where applicable, CMR parameters were indexed to BSA $^{1.3}$.

\section{Results}

The study sample consisted of 145 patients (64\% male). Median age at CMR was 16 years [IQR 11-23 years] and age at Fontan was 3.4 years [IQR 2.4-6.2 years]. Over a median follow-up of 4.6 years after CMR, 24 patients (17\%) reached the study endpoint (20 deaths, 4 transplant listings). The results of the CART analysis are shown in Figure 1. $\mathrm{EDV}_{\mathrm{i}}$ was the strongest predictor of transplant-free survival. In the more severely dilated subgroup $\left(E V_{i} \geq 135 \mathrm{~mL} / \mathrm{BSA}^{1.3}\right)$, worse GCS was the most important predictor of transplant-free survival (33\% vs. $75 \%$ with endpoint). However, in those with less dilation $\left(\mathrm{EDV}_{\mathrm{i}}<135 \mathrm{~mL} / \mathrm{BSA}^{1.3}\right), \mathrm{EF}<50 \%$ was the most important predictor but added little additional discrimination (9\% vs. $15 \%$ with endpoint). Figure 2 depicts a Kaplan-Meier plot with groups informed by the CART.

\section{Conclusions}

CMR-derived functional single ventricle $\mathrm{EDV}_{\mathrm{i}}$ is the strongest independent predictor of transplant-free survival in patients late after the Fontan operation. In patients with moderate or worse ventricular dilatation, GCS rather than EF has additional discriminating power for the endpoint. These data highlight the interactions between ventricular dilation and strain and the importance of CMR imaging in this population. 


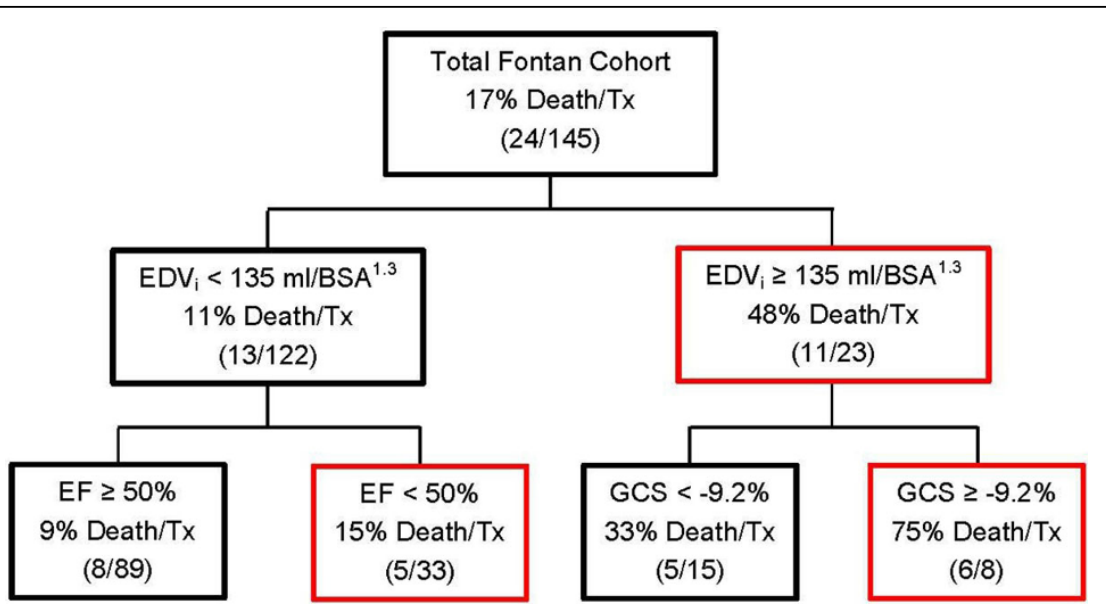

Figure 1 Classification and regression tree for death and transplant Tx in Fontan paients

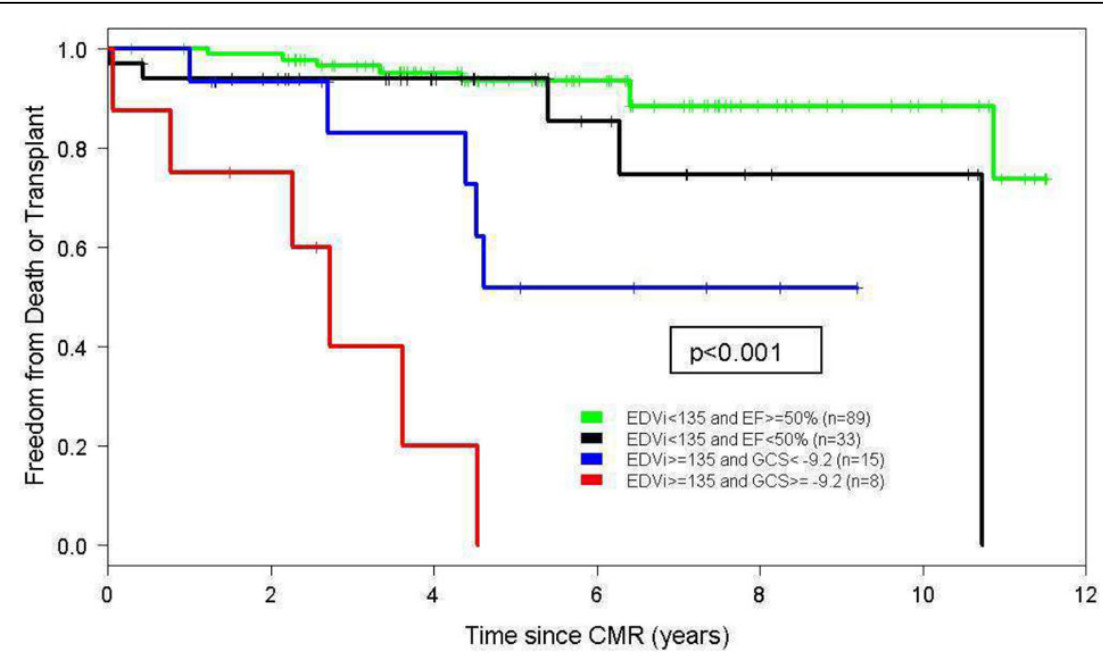

Figure 2 Freedom from death and transplant by risk factor subgroups.

\section{Authors' details}

${ }^{1}$ Cardiology, Boston Children's Hospital, Boston, MA, USA. ${ }^{2}$ Pediatrics, Harvard

Medical School, Boston, MA, USA.

Published: 27 January 2016

doi:10.1186/1532-429X-18-S1-029

Cite this article as: Rathod et al:: The relative importance and interactions of CMR-derived parameters of ventricular mechanics in the prediction of death and transplant late after the Fontan operation. Journal of Cardiovascular Magnetic Resonance 2016 18(Suppl 1):O29.
Submit your next manuscript to BioMed Central and take full advantage of:

- Convenient online submission

- Thorough peer review

- No space constraints or color figure charges

- Immediate publication on acceptance

- Inclusion in PubMed, CAS, Scopus and Google Scholar

- Research which is freely available for redistribution

Submit your manuscript at www.biomedcentral.com/submit 